\title{
An Analysis of Clinical Efficacy of Microsurgical Resection of Intradural Neoplasm by Unilateral Approach with Caspar Retractors
}

\author{
Xuan Wang Hong-Yang Zhao De-Qiang Lei Wen-De Zhu Ying-Chun Zhou \\ Department of Neurosurgery, Union Hospital, Tongji Medical College, Huazhong University of Science and \\ Technology, Wuhan, China
}

\section{Significance of the Study}

- The Caspar distraction device has advantages of smaller wound, less bleeding, fewer postoperative reactions, shorter hospitalization period, and faster recovery.

- Exposure of the tumor was not as adequate as that in the standard laminectomy group, especially in the management of ependymoma.

- For minimally invasive surgery, preoperative diagnosis is very important, and schwannoma or fibroma with length $<6 \mathrm{~cm}$ is the absolute indication for Caspar surgery.

\section{Keywords}

Caspar retractors $\cdot$ Intraspinal tumor $\cdot$ Efficacy analysis

\begin{abstract}
Objective: This study aims to investigate the clinical efficacy of minimally invasive microsurgical resection of intraspinal tumors with the aid of Caspar retractors. Materials and Methods: A total of 125 intraspinal tumor patients with lesions smaller than $6 \mathrm{~cm}$, who were treated at the Neurosurgery Department of our hospital from March 2010 to March 2016, were retrospectively analyzed. Among these, 73 patients underwent microsurgical resection of intraspinal tumors with the aid of Caspar retractors, while 52 patients underwent conventional laminectomy for resection of intraspinal tumors. Relevant indicators between both groups of patients were compared, including length of surgical inci-
\end{abstract}

\begin{tabular}{ll}
\hline KARGER & $\begin{array}{l}\text { C) } 2019 \text { The Author(s) } \\
\text { Published by S. Karger AG, Basel }\end{array}$ \\
karger@karger.com & This is an Open Access article licensed under the Creative Commons \\
www.karger.com/mpp & $\begin{array}{l}\text { Attribution-NonCommercial-4.0 International License (CC BY-NC) } \\
\text { (http://www.karger.com/Services/OpenAccessLicense), applicable to } \\
\text { the online version of the article only. Usage and distribution for com- } \\
\text { mercial purposes requires written permission. }\end{array}$
\end{tabular}

sion, duration of surgery, postoperative drainage volume, time to first out-of-bed activity after surgery, postoperative hospitalization period, visual analog score (VAS) score, and Japanese Orthopedic Association (JOA) score, at 1 month after surgery. Results: Compared with the conventional laminectomy group, patients who underwent microsurgical resection with the aid of Caspar retractors had better outcomes in terms of length of surgical incision, postoperative drainage volume, time to first out-of-bed activity after surgery, postoperative hospitalization period, and VAS scores $(p<0.05)$. However, JOA scores at 1 month after surgery did not have any significant differences $(p>0.05)$. Conclusions: The microsurgical resection of intraspinal tumors with the aid of Caspar retractors has advantages of small trauma, less bleeding, and faster recovery. It is a safe and efficacious method for treating small intraspinal tumors.

(C) 2019 The Author(s)

Published by S. Karger AG, Basel 


\section{Introduction}

Intraspinal tumors are common neurogenic neoplasms, which account for approximately $15 \%$ of central nervous system tumors $[1,2]$. Intraspinal tumors collectively refer to primary and metastatic tumors that grow in the spinal canal or spinal cord, or tissue structures adjacent to the spine (such as the spinal dura mater, nerve roots, blood vessels, and intraspinal adipose tissues). Practicing neurosurgeons will encounter patients with intraspinal tumors. Therefore, they need to be aware of their clinical presentation and diagnostic evaluation, the tumor types, management options, and frequency of treatment-related complications [3]. Treatment for most patients with primary intraspinal tumors includes inpatient hospital stay with surgery for biopsy or resection [4]. The traditional surgical procedures for resection of these pathologies involve subperiosteal muscle stripping, hemilaminectomy, or even extensive laminectomy $[5,6]$. For lesions that affect the foraminal regions, an additional ipsilateral facetectomy might be required [7]. However, this may necessitate, at least temporarily, external immobilizing, severe and prolonged postoperative pain, risk of late spine instability, and/or kyphosis [8], as well as persistent back pain [9]. For anteriorly placed tumors, the cord must be manipulated or rotated after section of the dentate ligament, with increased risk of neural damage. In order to prevent complications, alternative, less invasive surgical techniques are being developed by taking advantage of the passages in the bones of the spine and innovations in surgical instruments [10]. Despite the use of microsurgery and the development of minimally invasive techniques, the Caspar retractor does not appear to be very popular. Few papers mentioning its use for anterior cervical surgery have been published in the literature in recent years $[11,12]$. Furthermore, there are no data in the literature on the resection of intraspinal tumors with Caspar retractors. We report our experience on the minimally invasive removal of intraspinal tumors using Caspar retractors in 73 patients.

\section{Materials and Methods}

\section{Study Participants and Data Collection}

The present study comprised 73 intraspinal tumor patients, who had a lesion length smaller than $6 \mathrm{~cm}$ and were treated at the Neurosurgery Department of Wuhan Union Hospital from March 2010 to March 2016. One physician in our hospital was responsible for carrying out the resection of intraspinal tumors with the aid of Caspar retractors in 73 patients (Caspar minimally invasive group). These patients comprised 35 males and 38 females, with an average age of 48.4 years (range 18-80 years). Pathological results revealed
Table 1. Comparison of general information between the 2 groups of patients

\begin{tabular}{llll}
\hline General information & $\begin{array}{l}\text { Caspar } \\
\text { group }\end{array}$ & $\begin{array}{l}\text { Laminectomy } \\
\text { group }\end{array}$ & $p$ value \\
\hline Age, years & $48.4 \pm 4.35$ & $46.3 \pm 5.13$ & $0.26>0.05$ \\
Length of lesion, cm & $4.23 \pm 0.36$ & $4.44 \pm 0.31$ & $0.49>0.05$ \\
Cross-sectional area, cm $\mathrm{cm}^{2}$ & $1.73 \pm 0.52$ & $1.54 \pm 0.48$ & $0.32>0.05$ \\
JOA score & $26.3 \pm 0.46$ & $26.8 \pm 0.51$ & $0.63>0.05$ \\
\hline
\end{tabular}

Data are presented as mean $\pm \mathrm{SD}$.

that 24 patients had meningiomas, 45 had schwannomas, and 4 had neurofibromas. Among the 73 tumor patients, 42 patients had lesions at the lumbosacral segment, 23 at the thoracic segment, and 8 at the cervical segment. Furthermore, among the 73 patients, 70 patients had preoperative JOA evaluation scores within $25-28$ points, while 3 had scores within $20-24$ points. A total of 52 patients ( 28 males and 24 females) had conventional laminectomy (conventional laminectomy group), with an average age of 46.3 years (range 16-79 years). Pathological results revealed that among these 52 patients, 2 patients had enterogenous cysts, 17 had meningiomas, 30 had schwannomas, and 3 had neurofibromas. Among these 52 patients, 21 patients had lesions at the lumbosacral segment, 18 at the thoracic segment, and 13 at the cervical segment. For preoperative JOA evaluation scores, 50 patients had scores within $25-28$ points, while 2 had scores within 20-24 points. All patients underwent nonenhanced and enhanced MRI scans before surgery, and the length of the lesions were all below $6 \mathrm{~cm}$. None of the patients had a history of open spine surgery or mental illness. All of the patients could cooperate to complete the relevant studies. Comparison of general information between the 2 groups of patients is shown in Table 1 .

\section{Surgical Procedure}

Surgery methods for the Caspar group: patients were transferred into the operating theater and placed in the prone or semiprone position after general anesthesia. A soft cushion was placed below the chest and abdomen. If the lesion was at the cervical segment, a head frame was used for fixation, to ensure neck flexion. When the lesion was at the lumbar segment, the patient was placed in a position where the hips and knees were bent, in order to widen the laminar space and decrease bone resection. If the lesion was on the lateral side or lateroanterior side of the cervicothoracic segment of the spinal cord, a semi-prone position was adopted, allowing the lesion to be on top. The intraoperative electrophysiological monitor was connected, and a bedside X-ray machine was used to correctly locate the vertebral body where the lesion was located. Two Kirschner pins were used to mark the upper and lower segments of the vertebral body that contained the tumor, in order to confirm the center of the incision. Routine disinfection of the surgical drapes was carried out, a longitudinal incision of 3-5 cm was made at the midline, and the skin and subcutaneous tissues were successively dissected to expose the supraspinous ligament. Then, the muscle attachment points on the spinous processes at the ipsilateral side were dissected, a gauze was used for blunt dissection and to expose the lamina before the markers were replaced, and fluoroscopy positioning was carried out. After confirming the ac- 

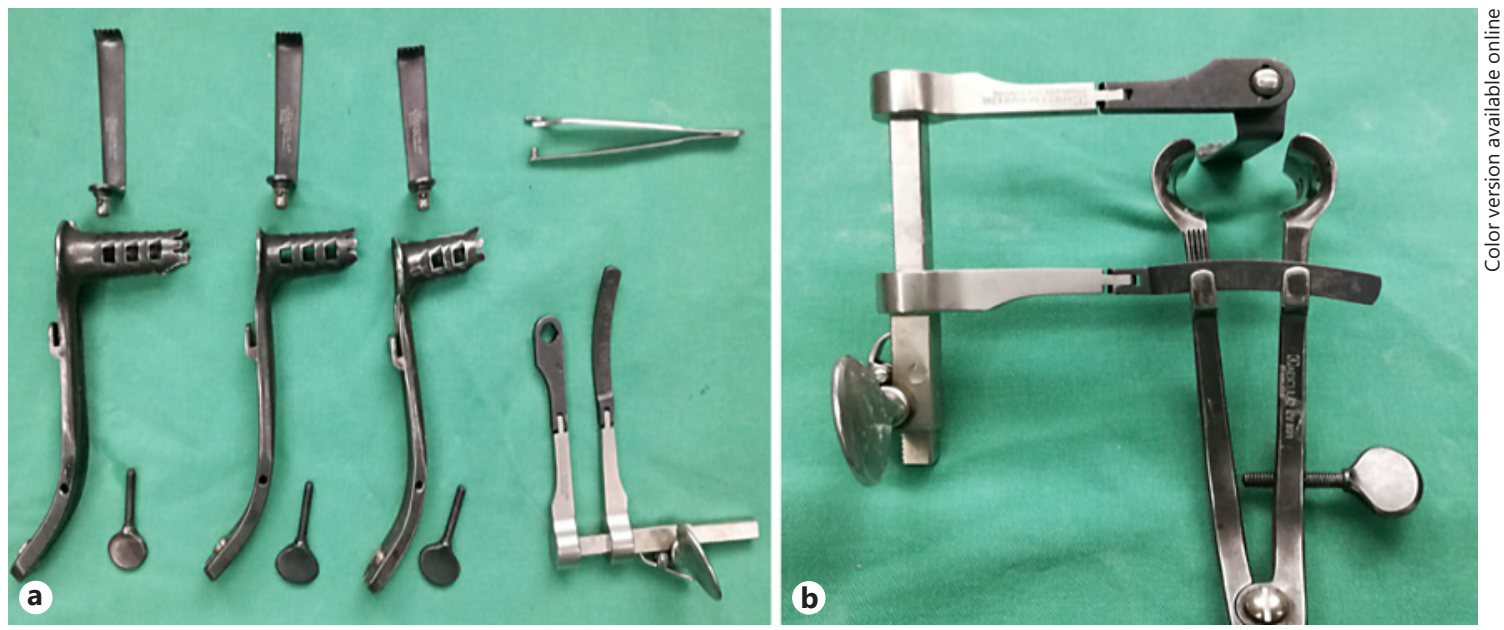

Fig. 1. Caspar retractor system. a Schematic diagram of various components of the Caspar retractor system. b Schematic diagram of the Caspar retractor system after assembly.

curacy of the segment, the Caspar retractors were placed and retracted. The Caspar retractor system is shown in Figure 1. The retraction range was determined by the length of the tumor. The maximum range of retraction was that which could expose the 2 vertebral bodies. Then, the transverse blades were placed on the surface of the paravertebral muscles, which were higher than the small articular processes, in order to prevent obstruction. Next, transverse retraction at the lateral side was carried out. If retraction was to be carried out on the thoracic segment, the blades were placed between the ribs to better expose the lesion. It was better when the transverse retraction could expose the outer edges of the facet joints. The microscope was attached, and a drill was used for fenestration laminectomy or semi-laminectomy. A laminectomy rongeur was used to remove the flaval ligament, in order to gradually expand the exposed area. For wider tumors, a drill was used for bone removal along the root of the spinous process. The contralateral lamina was removed to further and completely expand the volume of the spinal canal and allow the facilitation of surgical manipulations. After bone removal, a longitudinal incision was made on the dura, and silk threads were used to retract the dura to the 2 sides. Before retraction, an examination was carried out to confirm that there were no adhesions between the tumor and the interior of the dura. After dural retraction, direct treatment of the root of meningiomas located at the posterolateral side was carried out. If the meningioma was located at the lateral or anterior side of the spinal cord, the apical odontoid ligament was cut to expose the base of the tumor. For schwannomas and neurofibromas, the arachnoid mater was fully dissected to identify the upper and lower boundaries of the tumors. If the tumor did not adhere tightly to the surrounding nerve root or spinal cord, full dissection and resection was carried out. If the tumor was cystic, the drainage of cyst fluid made tumor resection easier. When the tumor was large or if the adhesion was severe, intratumor decompression was first carried out. Following that, the adhered nerve root and spinal cord along the interface of the tumor capsule and the arachnoid mater were separated. Complete hemostasis was carried out after the tumor resection, 5-0 absorbable sutures were used to tightly suture the dura, and the Caspar retractor was removed. Drainage tubes were implanted according to the situation before the incision was sutured layer by layer. Schematic diagrams of tumor resection and surgical site under the aid of the Caspar retractor are shown in Figure 2.

For conventional laminectomy, the patients were placed in the prone or semi-prone position after general anesthesia and connected to an electrophysiological monitor. X-ray films were used to locate the vertebral segment with the lesion. A posterior midline approach was adopted, and an incision of 8-10 $\mathrm{cm}$ was made. Then, the skin, subcutaneous adipose tissue, and muscle fascia were dissected layer by layer. Monopolar electrocautery was used to dissect the muscles along the spinous process, which were kept close to the lamina for separation. A laminectomy stripper was used to strip the muscles to the outside of the articular process. This was followed by retraction using the fossa retractor to expose the surgical field. A milling cutter was used to mill the lamina with a width not exceeding the articular process and a length exposing the upper and lower boundaries of the tumor. The flaval ligament and adipose tissues on the surface of the dura were removed, and bone wax was used for hemostasis by application on the edges of the bone window. Under a microscope, the transverse dissection of the dura was carried out to expose the tumor. The aforementioned method was used for the complete resection of the tumor. After resection, the dura was tightly sutured, and the lamina was replaced and fixed using titanium plates. Drainage tubes were implanted before the incision was sutured layer by layer.

\section{Postoperative Management}

All patients were given symptomatic treatment to prevent bleeding, acid suppression, and neurotonic discharges. Two days later, the drainage tubes were removed according to the drainage status of the patients. The drainage volume, time to first out-of-bed activity after surgery, and discharge time were recorded. Long periods of sitting and standing, and the carrying of heavy objects were prohibited within 1 month after the surgery. Periodic followups were conducted at 3 and 6 months, and at 1 year after surgery. 

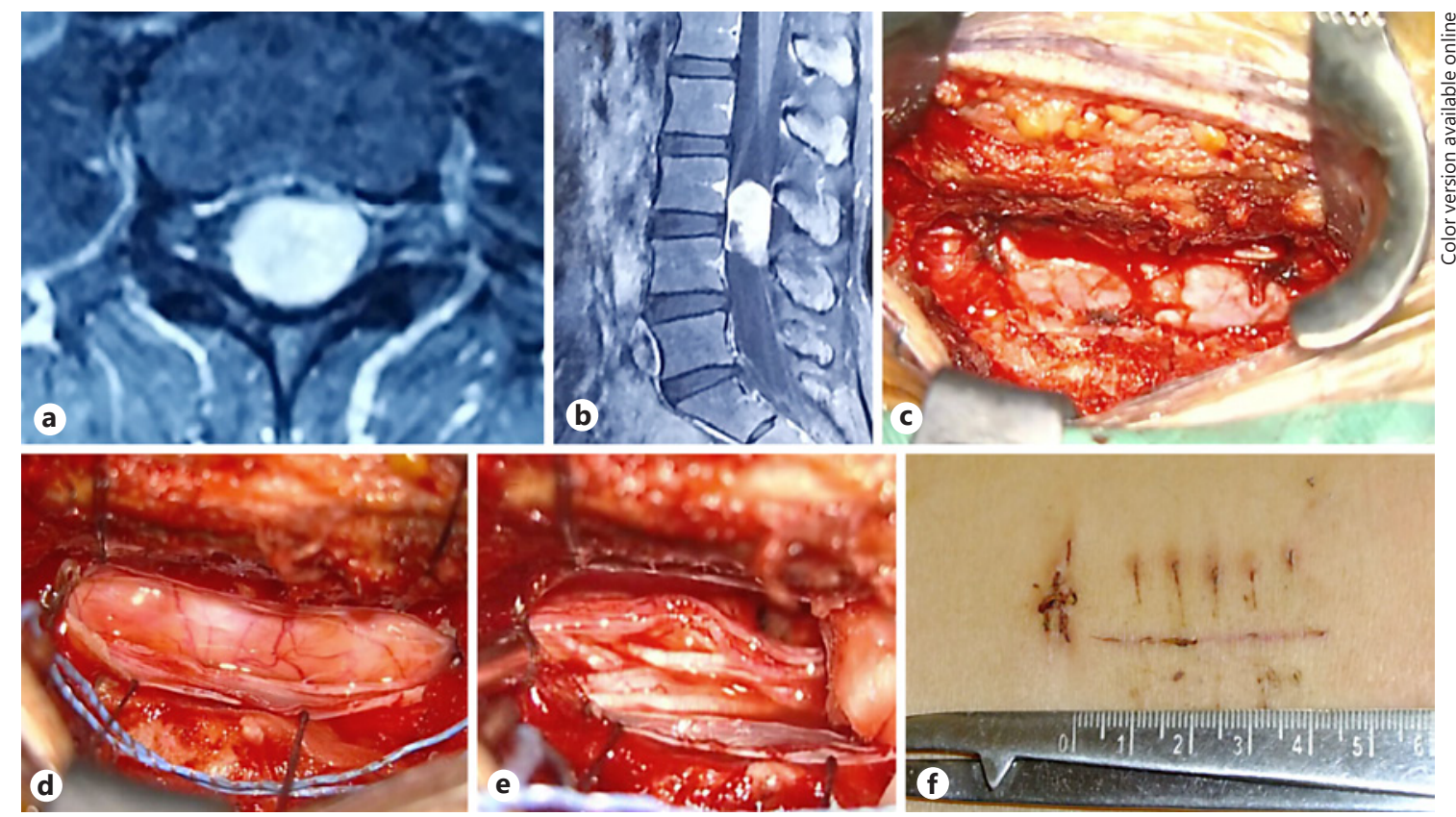

Fig. 2. Schematic diagram of tumor resection and surgical site under the aid of the Caspar retractor. a, b Imaging suggests schwannomas at the L2-L3 spinal canal. c Tumor after Caspar retraction. $\mathbf{d}$ Dura retraction to further expose the tumor. e The nerve root is well preserved after tumor resection. $\mathbf{f}$ The surgical wound is only $4 \mathrm{~cm}$ long.

Evaluation indicators include surgery duration, length of surgical incision, postoperative drainage volume, time to first out-ofbed activity, and postoperative hospitalization period. The visual pain simulation score of the patients was evaluated at week 1 and at months 1, 3, and 6 after surgery using the visual analog scale (VAS; $0-10$ points, where 0 indicates no pain, 10 indicates extreme pain, and middle scores indicate varying degrees of pain). The evaluation was carried out by the patient according to their self-perception. The Japanese Orthopedic Association (JOA) score was used at 1 month after surgery to evaluate improvement rates.

\section{Statistics}

Statistical processing was carried out using SPSS 13.0 statistical software (SPSS Inc., USA). Statistical analysis of data from the 2 groups was carried out. Quantitative data were expressed as mean \pm SD and intergroup comparison was carried out using $t$ tests. Qualitative data were expressed as frequency, and intergroup comparison was carried out using the $\mathrm{X}^{2}$ test. $p<0.05$ was considered statistically significant.

\section{Results}

All 125 patients completed the surgery. Among these patients, 119 patients underwent radical resection of the tumor. Radical resection was not carried out in 2 patients due to unclear boundaries between the enterogenous cysts and spinal cord, and in 4 patients because the meningiomas adhered tightly to the spinal cord and nerve root. All incision sites in the patient healed by first intention. Two patients in the open surgery group experienced cerebrospinal fluid leakage, and none of the patients developed infections or other complications. All patients underwent at least half a year of follow-ups.

Patients who underwent microsurgical resection with the aid of Caspar retractors had better outcomes in terms of the 5 major indicators (length of surgical incision, surgery duration, postoperative drainage volume, time to first out-of-bed activity after surgery, and mean hospitalization period), compared with patients who received conventional laminectomy, and the differences were statistically significant ( $p<0.05$, Table 2$)$.

VAS scores were used to compare the postoperative improvement status. It was found that self-perceived pain at 1 week and 1,3 , and 6 months after surgery were ameliorated in the Caspar minimally invasive group, compared with the conventional laminectomy group, and these differences were statistically significant $(p<0.05$, Table 3). There were no significant differences in JOA evaluation scores between these 2 groups. 
Table 2. Surgical indicators in the 2 groups

\begin{tabular}{lclllll}
\hline Group & $n$ & $\begin{array}{l}\text { Length of } \\
\text { incision, } \\
\mathrm{cm}\end{array}$ & $\begin{array}{l}\text { Surgery } \\
\text { duration, } \\
\mathrm{h}\end{array}$ & $\begin{array}{l}\text { Drainage } \\
\text { volume, } \\
\mathrm{mL}\end{array}$ & $\begin{array}{l}\text { Time to first } \\
\text { ground activity, } \\
\text { days }\end{array}$ & $\begin{array}{l}\text { Length of } \\
\text { hospitalization stay, } \\
\text { days }\end{array}$ \\
\hline Caspar group & 73 & $\begin{array}{l}4.1 \pm 1.22^{1} \\
8.7 \pm 1.68\end{array}$ & $\begin{array}{l}2.8 \pm 0.36^{1} \\
4.7 \pm 0.47\end{array}$ & $\begin{array}{l}180 \pm 15.7^{1} \\
270 \pm 18.3\end{array}$ & $\begin{array}{l}3.3 \pm 0.3^{1} \\
7.4 \pm 0.5\end{array}$ & $\begin{array}{r}7.7 \pm 1.2^{1} \\
12.5 \pm 1.4\end{array}$ \\
Laminectomy group & 52 & 0.015 & 0.018 & 0.005 & 0.008 \\
\hline$p$ value & & 0.021 & 0.015 & \\
\hline
\end{tabular}

Data are presented as mean \pm SD. ${ }^{1} p<0.05$.

Table 3. VAS scores in the 2 groups after surgery

\begin{tabular}{llllll}
\hline Group & $n$ & Week 1 & Month 1 & Month 3 & Month 6 \\
\hline Caspar group & 73 & $2 \pm 2^{1}$ & $1 \pm 2^{1}$ & $1 \pm 1^{1}$ & $1 \pm 0^{1}$ \\
Laminectomy group & 52 & $5 \pm 3$ & $3 \pm 2$ & $2 \pm 2$ & $1 \pm 2$ \\
\hline
\end{tabular}

Data are presented as mean \pm SD. ${ }^{1} p<0.05$.

\section{Discussion}

The widespread application of surgical microscopes and improvements in surgery instruments have greatly increased the safety of intraspinal tumor surgery and improved radical resection rates of tumors, which has significantly improved postoperative neurological functions in patients [13]. Although conventional open surgery has advantages in intraspinal tumor resection such as better exposure field and easier surgeon manipulation [14], it has shortcomings such as larger wound, greater bleeding volume, and more severe postoperative reactions. Due to extensive damage and destruction to the supraspinous ligament, spinous process, lamina, and other middle and posterior column structures of the vertebrae during conventional laminectomy [15], this approach has often resulted in decreased stability of the vertebrae after surgery and a tendency to develop spinal deformities [16].

Caspar retractors were first used in anterior cervical discectomy [17]. Considering its large retraction range and lower tissue injury, the present study was the first to apply Caspar retractors in the resection of intraspinal tumors, which has been rarely reported locally and overseas. Compared with conventional open laminectomy, the use of Caspar retractors can decrease the stripping of muscle attachment points, preserve the posterior tension zone of the spinous process, interspinous ligaments, and supraspinous ligaments, minimize damage to spinal stability, and decrease damage to the posterior column structures of the vertebrae to a minimum [18]. Meanwhile, this technique has advantages of smaller wound, less bleeding, fewer postoperative reactions, shorter hospitalization period, and faster recovery. Due to the absence of the need for lamina restoration and fixation, the hospitalization fees of the patient can be decreased. The 73 patients in the present study did not experience any complications associated with laminotomy, and most of these patients were able to get out of bed and move on the second day after surgery, and start functional training on the third day. After surgery, self-perceived pain was mild in all patients, and only 1 patient experienced cerebrospinal fluid leakage. The duration of hospitalization was also significantly decreased, when compared with the laminectomy group. During the follow-up period, no vertebral instability such as kyphosis or scoliosis occurred.

Caspar retractors can be used to obtain a larger space for manipulation through a smaller skin incision and can satisfy conventional microsurgical manipulation. However, this is not suitable for all tumors. The 73 patients selected for the present study had meningiomas, schwannomas, or fibromas. The 2 excluded patients had a preoperative $\mathrm{X}$-ray diagnosis of schwannomas. However, during surgery, it was found that the tumors originated from the central canal and had indistinct boundaries with the 
spinal cord. In consideration that these were ependymomas, the surgery was replaced by open surgery. Among the 73 patients, the length of the tumors in some patients was $6 \mathrm{~cm}$, and the width of the tumor could occupy the entire cross-sectional area of the spinal canal. Caspar retractors can completely expose the tumor, while the Quadrant channel can only expose tumors with a length of $5 \mathrm{~cm}$ or less and a cross-sectional area $<2 / 7$ of the area of the spinal canal [19]. Therefore, Caspar retractors have an advantage over Quadrant retractors for the exposure of large-area tumors. In the selection of surgical sites, Caspar retractors are the most suitable for lumbar vertebral surgery, because a midline incision or paramedian incision can be chosen. If the tumor tends to grow towards one side, the Wiltse muscle-splitting approach can be used. This would result in less muscle damage and less impact on vertebral stability. Compared with conventional laminectomy, minimally invasive surgery has a higher demand for preoperative tumor localization. Bedside X-rays are recommended that are carried out before skin incision and after bone exposure to accurately confirm the segment where the tumor is located. This would allow for the facilitation of the exposure of the entire area of the tumor after the Caspar retractor is opened. If the localization is not accurate, the full length of the tumor cannot be completely exposed after retraction, and the incision would have to be extended. This would increase unnecessary bone removal and destruction to the structural stability of the vertebrae.

Compared with open surgery, minimally invasive surgery has higher technical requirements for manipulation and is more challenging $[20,21]$. Surgeons who are able to conduct Caspar minimally invasive surgeries are generally well trained to conduct open tumor resection, while minimally invasive surgery requires a certain period of learning. Even though the mastery of minimally invasive surgery is not easy, with the accumulation of surgical experience, the duration of the surgery can be significantly shortened. In addition, after the initial learning curve, minimally invasive surgery will be an effective and reliable choice for surgeons.

\section{Conclusion}

The Caspar distraction device has advantages of smaller wound, less bleeding, fewer postoperative reactions, shorter hospitalization period, and faster recovery. Exposure of the tumor was not as adequate as that in the standard laminectomy group, especially in the management of ependymoma. For minimally invasive surgery, preoperative diagnosis is very important, and schwannoma or fibroma with length $<6 \mathrm{~cm}$ is the absolute indication for Caspar surgery.

\section{Statement of Ethics}

The authors have no ethical conflicts to disclose.

\section{Disclosure Statement}

The authors have no conflicts of interest to disclose.

\section{References}

1 Weber C, Gulati S, Jakola AS, Habiba S, Nygaard ØP, Johannesen TB, et al. Incidence rates and surgery of primary intraspinal tumors in the era of modern neuroimaging: a national population-based study. Spine. 2014 Jul;39(16):E967-73.

2 Wilartratsami S, Muangsomboon S, Benjarassameroj S, Phimolsarnti R, Chavasiri $\mathrm{C}$, Luksanapruksa P. Prevalence of primary spinal tumors: 15-year data from Siriraj Hospital. J Med Assoc Thai. 2014 Sep;97 Suppl 9:S83-7.

3 Lee SE, Jahng TA, Kim HJ. Different surgical approaches for spinal schwannoma: a single surgeon's experience with 49 consecutive cases. World Neurosurg. 2015 Dec;84(6):1894902.
4 Engelhard HH, Villano JL, Porter KR, Stewart AK, Barua M, Barker FG, et al. Clinical presentation, histology, and treatment in $430 \mathrm{pa}$ tients with primary tumors of the spinal cord, spinal meninges, or cauda equina. J Neurosurg Spine. 2010 Jul;13(1):67-77.

5 Yu Y, Hu F, Zhang X, Gu Y, Xie T, Ge J. Application of the hemi-semi-laminectomy approach in the microsurgical treatment of C2 schwannomas. J Spinal Disord Tech. 2014 Aug;27(6):E199-204.

6 Chowdhury FH, Haque MR, Sarker MH. High cervical spinal schwannoma; microneurosurgical management: an experience of 15 cases. Acta Neurol Taiwan. 2013 Jun;22(2): 59-66.
7 Li WS, Chen C, Wang H, Liang CF, Luo L, Guo Y. Hemilaminectomy approach combined with in situ restoration of vertebral laminae for thoracic intraspinal tumors. Turk Neurosurg. 2013;23(5):630-8.

8 Ahmed R, Menezes AH, Awe OO, Mahaney $\mathrm{KB}$, Torner JC, Weinstein SL. Long-term incidence and risk factors for development of spinal deformity following resection of pediatric intramedullary spinal cord tumors. J Neurosurg Pediatr. 2014 Jun;13(6):613-21.

9 Tarantino R, Donnarumma P, Nigro L, Rullo M, Santoro A, Delfini R. Surgery of intradural extramedullary tumors: retrospective analysis of 107 cases. Neurosurgery. 2014 Nov;75(5): 509-14. 
10 Smith ZA, Aoun SG, Y El Ahmadieh T, Wong AP, Lall RR, Bendok BR, et al. Minimally invasive resection of a high-thoracic intradural extramedullary tumor: an operative 3-D video. Neurosurgery. 2013 Sep;73(1 Suppl Operative):ons1.

11 Millward CP, Bhagawati D, Chan HW, Bestwick J, Brecknell JE. Retrospective observational comparative study of hemilaminectomy versus laminectomy for intraspinal tumor resection; shorter stays, lower analgesic usage and less kyphotic deformity. Br J Neurosurg. 2015 Jun;29(3):390-5.

12 Seex KA. An anterior cervical retractor utiliz ing a novel principle. J Neurosurg Spine. 2010 May;12(5):547-51.

13 Li H, Weng Y, Zhou D, Nong L, Xu N. Experience of operative treatment in 27 patients with intraspinal neurilemmoma. Oncol Lett. 2017 Oct;14(4):4817-21.
14 Millward CP, Bhagawati D, Chan HW, Bestwick J, Brecknell JE. Retrospective observational comparative study of hemilaminectomy versus laminectomy for intraspinal tumor resection; shorter stays, lower analgesic usage and less kyphotic deformity. Br J Neurosurg. 2015 Jun;29(3):390-5.

15 Geng XP, Wang X, Meng T, Li JJ, Li XC, Fu GY. The influence of posterior approach cervical intraspinal tumor resection on the stability of cervical vertebra. J Biol Regul Homeost Agents. 2015 Apr-Jun;29(2):389-94.

16 Arora N, Grenier SG. Acute effects of whole body vibration on directionality and reaction time latency of trunk muscles: the importance of rest and implications for spine stability. J Electromyogr Kinesiol. 2013 Apr;23(2):394401.

17 Fransen P. A simplified technique for anterior cervical discectomy and fusion using a screwplate implanted over the Caspar distractor pins. Acta Orthop Belg. 2010 Aug;76(4):546-
18 Zong S, Zeng G, Du L, Fang Y, Gao T, Zhao J. Treatment results in the different surgery of intradural extramedullary tumor of 122 cases. PLoS One. 2014 Nov;9(11):e111495.

19 Chen C, Bao G, He BX. Comparison of the efficacy of intraspinal tumor resection under quadrant channel and hemilaminectomy surgery. Journal of Xi'an Jiao-tong University. Med Sci. 2016;37:183-6.

20 Lau D, Chou D. Posterior thoracic corpectomy with cage reconstruction for metastatic spinal tumors: comparing the mini-open approach to the open approach. J Neurosurg Spine. 2015 Aug;23(2):217-27.

21 Arts MP, Wolfs JF, Kuijlen JM, de Ruiter GC. Minimally invasive surgery versus open surgery in the treatment of lumbar spondylolisthesis: study protocol of a multicentre, randomised controlled trial (MISOS trial). BM] Open. 2017 Nov;7(11):e017882. 